\title{
Reflexões sobre as diferentes facetas do ócio nos tempos contemporâneos
}

\section{Reflections on the different sides of idleness in contemporary times}

\author{
Reflexiones sobre las diferentes facetas del ocio en la época \\ contemporánea
}

\author{
Patrícia Zaczuk Bassinello ${ }^{1}$ \\ Valdemir Miotello ${ }^{2}$
}

\begin{abstract}
Resumo: Ao longo do último século, o ócio experimentou um processo de modernização e democratização, especialmente com a crise de uma sociedade centrada no trabalho - o período Pós-Revolução Industrial - e o surgimento de novas ideias que colocam o tempo livre, o ócio e o lazer no papel de elementos estruturantes do novo contexto social e como práticas para novos modos de vida. Neste trabalho, procuramos dar foco aos aspectos significativos da realidade e função do ócio em nossa época, esclarecendo sua relação com os processos de inovação pessoal, social e econômica, estabelecendo um equilíbrio de nossos atos no pensar o ócio e trabalho, e ócio e vida, a partir de diferentes ângulos de abordagem. Para analisar esse fenômeno, baseamo-nos em fontes científicas representativas na área, de modo a elaborarmos uma visão ampliada do assunto, a partir de contribuições da perspectiva bakhtiniana. Observamos que o aumento das opções de lazer, nas últimas décadas do século XX, somado ao crescimento dos estudos do fenômeno ócio e suas possibilidades, permitiu uma evolução de seus conceitos, desde atividades ou práticas ligadas ao consumo, ao ócio digital, até ser entendido como experiência que tem como chave de discussão o sujeito que vive essas experiências. Acreditamos que essa reflexão sobre o ócio abra possibilidades de entender seu espaço no campo das ciências sociais e humanas e, de forma especial, na sua contribuição a uma nova postura de produção relacional, que estimule uma sociedade que crie e inove bens e serviços e que aprofunde os estudos do ócio, desde o horizonte experiencial dinâmico até o direito à alteridade, ao tempo de alteridade - própria e do outro - enquanto "direito à infuncionalidade", da escuta da palavra outra.
\end{abstract}

Palavras-chave: Bakhtin. Infuncionalidade. Significações do ócio. Tempo de alteridade.

Abstract: Over the last century, idleness experienced a modernization and democratization process especially with the crisis of a society focused on work - the post-Industrial Revolution - and the emergence of new ideas that put the free time, the leisure and recreation in the role of structural elements of the new social context and like tools for the new ways of life. In this work, we we seek to focus on the significant aspects of reality and function of leisure in our time, clarifying their relationship with the processes of personal, social and economic innovation by establishing a balance of our acts in thinking the leisure and work and leisure and life from different angles of approach. In order to analyze this

1 Universidade Federal de Mato Grosso do Sul - campus Aquidauana Graduação em Turismo pela PUC-Campinas, Mestre em Educação pela UNIMEP e Doutoranda em Ciência, Tecnologia e Sociedade pela UFSCar. E-mail: pzbassinello@yahoo.com.br

2 Universidade Federal de São Carlos Doutor e Mestre em Lingüística pela Unicamp, Graduação em Filosofia pela Pontifícia Universidade Católica do Rio Grande do Sul. Docente do Programa de Pós-Graduação em Ciência, Tecnologia e Sociedade e do Programa de Pós-Graduação em Lingüística da UFSCar. E-mail: miotello@terra.com.br 
phenomenon, we were based on scientific sources which are representative in the context, and then we elaborated a general overview of the subject from the contributions of the bakhtinian perspectives. We observed that the increase in leisure options in the last decades of the twentieth century, along with the growth of the studies of the idleness phenomenon and its possibilities, allowed an evolution of its concepts, from activities or practices associated to the consumption and to digital entertainment, to its understanding as an experience whose key of the discussion is the subject living these experiences. We believe that this reflection about idleness may open possibilities of a better comprehension of its insertion in the social and human sciences field and, especially, in its contribution to a new attitude of the relational production, centered on the subject, which stimulates a society that creates and innovates goods and services and who deepens the studies of leisure from the dynamic experiential horizon to the right to the otherness and to its time - the own one and the others' - such as "the right to unfunctionality", from listening to the other word.

Keywords: Bakhtin. Unfunctionality. Meanings of idleness. Otherness time

Resumen: Durante el último siglo, ociosidad experimentó un processo de modernización y democratización especialmente con la crisis de una sociedad centrada en el trabajo - la revolución postindustrial y el surgimiento de nuevas idéias que ponen el tiempo libre, ocio y recreación en el papel de elementos estructurales del nuevo contexto social y cómo practicar nuevas formas de vida. Em este artículo tratamos de enfoque a los aspectos significativos de la realidad y la función de ocio en nuestro tiempo, aclarar su relación con los procesos de innovación personal, social y económico mediante el establecimiento de un equilibrio de nuestros actos en el pensamiento del trabajo y ocio, ocio y vida desde diferentes ángulos de enfoque.Para analizar este fenómeno, contamos con representante de fuentes científicas en el área con el fin de elaborar una visión ampliada del tema de lãs contribuciones de perspectiva bakhtiniana. Observamos que el aumento de possibilidades de ócio en las últimas décadas del siglo XXI, junto con el crecimiento de los estudios sobre el fenômeno y sus possibilidades de ocio, permite una evolución de sus conceptos de actividades relacionadas con el consumo e las prácticas, al entretenimiento digital, debe ser entendida como un experimento que tiene como clave el tema de discusión viviendo estas experiéncias. . Creemos que esta reflexión acerca de las posibilidades abiertas de ocio entender su espacio en el campo de las ciencias sociales y humanas y, en particular, de su contribución a una nueva postura de producción relacional, que estimula una sociedad que deba crear e innovar bienes y servicios y profundizar en los estudios de ocio desde el horizonte experiencial dinâmico hasta el derecho a la alteridad en el momento de la alteridad - propia y del outro, mientras que "infuncionalidad" de la escucha dela palabra otra.

Palabras clave: Bakhtin. Infuncionalidad,significados de ócio. Ttiempo de la alteridad.

\section{INTRODUÇÃO}

A compreensão do fenômeno do ócio remete a uma discussão antiga em nossa história; porém, ressurge na contemporaneidade e vem se transformando ao longo do tempo em um assunto cada vez mais complexo, com novas significações e releituras que permeiam as condições do contexto social vigente.

Apesar de sua antiguidade, somente após a Revolução Industrial, o ócio vem aderindo a sentidos distintos, a novos contextos, e sendo vinculado a diferentes práticas. Isso vem ocorrendo, especialmente, após o surgimento do tempo livre, desconectado do tempo-espaço de trabalho e, cada vez mais, conectado a uma perspectiva da experiência humana.

Neste trabalho, propusemo-nos a refletir sobre as transformações, o crescimento e os aspectos concebidos ao fenômeno do ócio em nossa época. Para demonstrar os aspectos significativos da realidade do ócio de hoje com diferentes ângulos de abordagem, apoiamo-nos em analisar esse fenômeno, no âmbito científico, a partir das contribuições de alguns autores e pesquisadores, de distintas áreas de conhecimento, que trabalham ou colaboram com o Instituto 
de Estudos do Ócio da Universidade de Deusto, em Bilbao - Espanha, o qual iniciou sua trajetória nesses estudos em 1988. Os demais pesquisadores que colaboram para os estudos são de outras universidades espanholas e estrangeiras, enriquecendo a discussão a partir de uma perspectiva interdisciplinar, aberta e global. A maioria de tais investigações encontra-se reunida no periódico Arbor: Ciência, Pensamento e Cultura (2012), em um número especial do dossiê dedicado ao Ócio no século XXI, intitulado "Reflexiones sobre el ocio en el siglo XXI". A escolha dessa fonte pautou-se no fato de se tratar de um dos primeiros periódicos dedicados aos temas dos estudos sociais da ciência e tecnologia, pela sua representatividade na comunidade científica como instrumento de informação de temas atuais e de máximo interesse, e por apresentar, nesse dossiê, um número especial sobre ócio, com artigos de pesquisadores e estudiosos que contribuem com suas reflexões a partir de diferentes áreas de conhecimento e complementares, caracterizando a perspectiva da interdisciplinaridade.

Também provocamo-nos a colaborar com esse tema nutrindo nossas reflexões com o pensamento de Mikhail Bakhtin (2006) que nos desperta para uma "revolução em diálogo com o momento contemporâneo", a partir de suas contribuições no eixo de "compreensão respondente", para usar uma expressão de Bakhtin, em relação a si mesmo, aos outros e ao mundo, referindo-se a sua filosofia da ação responsável, como também no deslocamento de sua atenção, em diversos problemas e campos, da identidade à alteridade. E, para essa reflexão, abstemo-nos apenas em despertar uma inversão de olhar, centrando sua contribuição para o ócio como direito à alteridade, ao tempo de alteridade - própria e do outro - enquanto "direito à infuncionalidade" (Ponzio, 2010; 2013), da escuta da palavra outra.

Em nossas investigações, não nos debruçamos em refletir com profundidade as aproximações ou naturezas distintas que os fenômenos do lazer e o termo tempo livre possam estabelecer com o fenômeno ócio ${ }^{3}$, haja vista a amplitude que os termos possibilitam pelos sentidos diversos que tomam; mas destacar que, para o recorte que nos propusemos olhar, nosso enfoque é no ócio.

Iniciaremos esse processo, destacando as concepções e práticas de ócio vigentes até o atual século e, posteriormente, apresentaremos nosso ponto de vista para este fenômeno.

3 Sobre as aproximações e distinções entre os fenômenos ócio e lazer e o termo tempo livre ver AQUINO, C.A B. e MARTINS, J. C. de O. Ócio, lazer e tempo livre na sociedade do consumo e do trabalho. In Revista Mal-Estar e Subjetividade. Fortaleza. VII. n2. Set/2007. ${ }^{4}$ Para saber das principais linhas de estudo do ócio ver Ritchie,J.R.B e Hudson, S. Understanding and meeting the challenges of consumer/tourist experience research. In International Journal of Tourism Research, v 11: 111-126. . Para conhecer o que significa "turismo de experiência", seus fatores determinantes, sua importância e suas consequências para a sociedade, ler Panosso Netto, A e Gaeta, C. (orgs) Turismo de experiência. São Paulo: Editora Senac São Paulo, 2010. ${ }^{6}$ Nesta pesquisa, para conceder o significado atribuído ao tempo livre/ócio, as autoras partiram, no questionário aplicado, de limitar a definição às seguintes opções: "relaxar-se", "conhecer gente agradável", "fazer o que eu quero" e "aprender algo". Estas quatro definições se referem a quatro dimensões ou formas de entender o tempo livre/ócio: o ócio como momento de descanso e desconexão; o ócio vinculado a relações sociais; o ócio associado a um comportamento individualista e mais isolado, liberado de controles hierárquicos; e por último, o ócio como um tempo também produtivo e de enriquecimento pessoal através da formação e aprendizagem. 


\section{0 ÓCIO COMO EXPERIÊNCIA}

Ao longo do último século, o ócio experimentou um processo de modernização e democratização, especialmente com a crise de uma sociedade centrada no trabalho - o período Pós-Revolução Industrial - e o surgimento de novas ideias que colocam o tempo livre, o ócio, o turismo e o lazer no papel de elementos estruturantes do novo contexto social e como práticas para novos modos de vida.

No século passado, os movimentos e reivindicações dos trabalhadores abriram caminhos para um tempo livre associado ao descanso e às férias, que culminaram na Declaração Universal dos Direitos Humanos de 1948, em seu artigo 24, que marca o direito de todo assalariado a usufruir de descanso e desfrutar do tempo livre em suas férias periódicas.

De acordo com Cuenca Amigo (2012), a primeira fase dos Estudos do Ócio está estreitamente vinculada à Sociologia ocupacional do trabalho, com base principalmente em uma análise das práticas e dos usos do tempo.

A popularização do tempo livre acabou por confundir o sentido do ócio, relacionando-o com o tempo de descanso necessário para recuperar-se do tempo de trabalho. Isso se deu exclusivamente como consequência da era industrial. Hoje, ainda, algumas práticas são pensadas com esta ligação do ócio ao tempo livre; mas já percebemos esse rompimento gradativo, o qual demonstraremos adiante.

Com a evolução do conhecimento desse fenômeno e suas possibilidades, como também suas práticas ligadas aos múltiplos divertimentos, permitiu-se observar uma mudança conceitual mais profunda, deslocando-se de uma visão objetivista do ócio como tempo livre e fortalecendose a compreensão do ócio como experiência, constatando-se o abundante uso da expressão "experiência de ócio" na bibliografia do momento.

Cuenca Cabeza e Goytia Prat (2012) ressaltam que as primeiras aproximações ao conceito de experiência encontram-se nas pesquisas desenvolvidas pelo Instituto dos Estudos do Ócio, que datam da década de 1990 do século XX. Realizavam-se a partir de sua aproximação com os aspectos psicológicos, vinculando-o ao bem-estar e à satisfação das necessidades psicológicas. Esta visão, que constitui uma referência norte-americana e que opta pelos termos "experiência" e "vivência", reflete uma perspectiva subjetiva do ócio, desenvolvendo uma teoria até hoje aceita e apropriada.

Seus pressupostos fundamentam que o desfrute do ócio ajuda a satisfazer as necessidades psicológicas básicas, especialmente aquelas que não se satisfazem em lugares e momentos de não ócio (Cuenca e Goytia, 2012, p266). A satisfação que proporciona o ócio permite a vitalidade do homem e de seu crescimento pessoal, ajudando a manter e a aumentar a sua saúde física e mental. O que importa nessa perspectiva é a consideração da experiência do ócio como um estado mental que resulta da relação entre o sujeito que participa e seu entorno, carregando consigo uma carga semântica de vivência, que fundamenta e se relaciona com a própria experiência. 
Cuenca Amigo (2012) ressalta que o uso do termo "vivência" refere-se àquilo que se experimenta de um modo imediato e que não desaparece no fluxo indistinto e trivial do que vivemos, mas tem relevância e totalidade para o sentido da nossa própria vida.

O século XIX revaloriza o conceito de vivência. No início, sua definição era oposta à de experiência. Aparecia como um refúgio das emoções, de imediatas fugas e do satisfatório. Com a pós-modernidade, tem-se outro tipo de organização da sociedade: aquela que está mais aberta à busca de vivências por parte dos indivíduos e também à procura de diversificadas experiências.

Essa forma de organização social muda a mentalidade e as condições de vida, entendendo certas formas de ócio como vivência, caracterizada por sua descontinuidade, espontaneidade e falta de sistema (Cuenca Amigo, 2012, p.323).

Percebemos essa relação de experiência e vivência para o ócio, quando a vivência começava a aparecer ao indivíduo como uma prática que se distingue por sua especial intensidade e centralidade da experiência cotidiana. É este o modo de experiência que se vive e se percebe paradigmaticamente nas formas contemporâneas de ócio.

Desde então, o ócio vem sendo definido como uma área específica da experiência humana, com seus benefícios e elementos próprios. E ao ser entendido como experiência da pessoa e fenômeno da sociedade contemporânea, tem se nutrido de muitas frentes disciplinares, para compreendê-lo em sua globalidade.

\begin{abstract}
“...o ócio, visto em toda a sua amplitude e desde um ponto de vista geral, é uma área de experiência, um recurso de desenvolvimento, uma fonte de saúde e preservação de enfermidades físicas e psíquicas, um direito humano que cobre as condições básicas da vida, um símbolo de qualidade de vida e um possível potencial econômico." (Trecho traduzido de Cuenca Amigo, 2012, p.324).
\end{abstract}

Essa visão foi aceita tanto pela Europa anglosaxã quanto pela mediterrânea. A partir desse momento, a visão se amplia e se torna complexa, apresentando diversas vertentes e linhas de estudos ${ }^{4}$. Dentre algumas, podemos destacar, conforme nosso objetivo, aquelas centradas em trabalhos conceituais ou de investigação da essência do que seja "experiência de ócio" e aquelas que exploram a natureza das práticas que facilitam a vivência da experiência de ócio.

Paralelamente à visão psicológica comentada, também esbarramo-nos com o olhar economicista para o ócio, tendo à frente Jeremy Rifkin (2001) e Pine II y Gilmore (1999), que

4 Para saber das principais linhas de estudo do ócio ver Ritchie,J.R.B e Hudson, S. Understanding and meeting the challenges of consumer/tourist experience research. In International Journal of Tourism Research, v 11: 111-126. ${ }^{5}$ Para conhecer o que significa "turismo de experiência", seus fatores determinantes, sua importância e suas consequências para a sociedade, ler Panosso Netto, A e Gaeta, C. (orgs) Turismo de experiência. São Paulo: Editora Senac São Paulo, 2010. ${ }^{6}$ Nesta pesquisa, para conceder o significado atribuído ao tempo livre/ócio, as autoras partiram, no questionário aplicado, de limitar a definição às seguintes opções: "relaxar-se", "conhecer gente agradável", "fazer o que eu quero" e "aprender algo". Estas quatro definições se referem a quatro dimensões ou formas de entender o tempo livre/ócio: o ócio como momento de descanso e desconexão; o ócio vinculado a relações sociais; o ócio associado a um comportamento individualista e mais isolado, liberado de controles hierárquicos; e por último, o ócio como um tempo também produtivo e de enriquecimento pessoal através da formação e aprendizagem. 
direcionam a concepção de ócio não somente enquanto um produto ou serviço da economia, mas ampliando-a para o processo de experiência, para a customização da própria experiência, isto é, o de engajar e lidar com sensações, heranças culturais e opções pessoais memoráveis.

“(...) as experiências constituem o núcleo dos espetáculos abarcando muitas experiências novas. (...) as origens desta expansão das experiências remonta de um homem e companhia por ele fundada: Walt Disney" (Pine II e Gilmore, 1999, p.20).

Conforme Fernández Villarán Ara (2012), é neste século XXI que nasce a interação entre economia e ócio. Essa perspectiva configura o ócio como um setor cada vez mais importante na economia e como uma alternativa de desenvolvimento em regiões com problemas estruturais nos seus setores produtivos tradicionais. Para ela, a maior parte das "indústrias de ócio", à exceção da fabricação de elementos para a prática de atividades de ócio, insere-se no setor de serviços e este já representa uma média de 70\% do PIB (Produto Interno Bruto) dos países da OCDE (Comunidade Econômica Europeia) e 62\% na Espanha.

Essa contribuição resulta na terceirização das economias e na alteração da estrutura de preferências das atividades, não somente para os países desenvolvidos mas também para aqueles em desenvolvimento, com a exportação de bens e serviços, abrindo possibilidades de diversificação e realização do ócio.

A perspectiva da economia da experiência remete-nos a pensar nas práticas de ócio que facilitam o sentido e significação que alcançam a vivência da experiência de ócio. Como práticas, podemos relacionar aquelas ligadas à natureza das atrações (esportivas, turísticas, lúdicas, culturais e de entretenimento), dos produtos e serviços e dos meios de comunicação (uso constante e massivo das TIC's- Tecnologias da Informação e Comunicação). A vivência dessas práticas está fundamentada na experiência e, hoje, caracterizada em uma perspectiva individual e personalizada.

O ócio também é experienciado pelas viagens. Aqui abrimos parênteses para o fenômeno do Turismo - das viagens - em que também, nos últimos anos, vem se discutindo o turismo de experiência ${ }^{5}$, seja como aprofundamento filosófico na relação entre experiência e turismo, e entre viagem e experiência, assim como também pela perspectiva de segmentação do mercado turístico.

No Turismo, a viagem como experiência é intensa e remete às condições específicas e à própria subjetividade. Implica imaginação, emoção e conhecimento. Consiste em descobrir-se a si

5 Para conhecer o que significa "turismo de experiência", seus fatores determinantes, sua importância e suas consequências para a sociedade, ler Panosso Netto, A e Gaeta, C. (orgs) Turismo de experiência. São Paulo: Editora Senac São Paulo, 2010. ${ }^{6}$ Nesta pesquisa, para conceder o significado atribuído ao tempo livre/ócio, as autoras partiram, no questionário aplicado, de limitar a definição às seguintes opções: "relaxar-se", "conhecer gente agradável", "fazer o que eu quero" e "aprender algo". Estas quatro definições se referem a quatro dimensões ou formas de entender o tempo livre/ócio: o ócio como momento de descanso e desconexão; o ócio vinculado a relações sociais; o ócio associado a um comportamento individualista e mais isolado, liberado de controles hierárquicos; e por último, o ócio como um tempo também produtivo e de enriquecimento pessoal através da formação e aprendizagem. 
mesmo, assumir sua história pessoal e, ainda, escolher os caminhos de sentido e significado da vida (Trigo, 2010, p.37).

Panosso Netto (2010) também convida-nos a pensar que a experiência turística pode alargar o conhecimento humano e modificar, de forma positiva, o modo de pensar, pois o turista, no proveito das viagens, busca uma prática contextualizada de seu ato, que, por sua vez, deve ser consciente. "Assim é que surgem novos paradigmas no ato do conhecer, do fazer, do se envolver com o Turismo, com o outro e consigo mesmo" (Panosso Netto, 2010, p.46). Esta relação origina uma gama de posturas e descobertas que é proporcionada e embasada na e pela experiência.

Nesse contexto experiencial, retornando a reflexão para o ócio, percebemos o quanto ele vem representando um valor indiscutível na sociedade atual.

Conforme Fradua e Cabrera (2012), a partir da análise e interpretação dos dados extraídos de uma pesquisa de "valores europeus" e sua aplicação na Europa, Espanha e país Basco sobre a relação de importância e significado atribuído ao ócio, tem-se revelado que este é quase entendido como um sinônimo do tempo livre. Esta pesquisa indica que existe uma significativa relação entre a vivência e percepção do trabalho remunerado e a significação outorgada ao ócio 6 .

\footnotetext{
"Na sociedade atual, o tempo livre/de ócio tem passado a ser uma esfera cada vez mais significativa da vida afirmando-se não somente como uma atrativa possibilidade, mas como um valor em si mesmo, enquanto que o trabalho vem perdendo parte de sua centralidade sobre todo o período estudado (1999-2008)" (Trecho traduzido de Fradua e Cabrera, 2012, p.290).
}

Os diferentes padrões culturais e, sobretudo, os diferentes níveis socioeconômicos e de bem-estar sociopolítico enfatizam essa relação latente, ao nível valorativo, entre trabalho e ócio. Além disso, observam que as novas gerações e aqueles que têm estudos no nível secundário e superior são os que valoram, em maior medida, o ócio. Isso ocorre, possivelmente porque lhe atribuem uma diferente significação e definição, ligada não à sobreposição a outros tempos, mas a um tempo que seja ativo.

Os Estudos do Ócio também se preocupam com as práticas do ócio entre coletivos, como, por exemplo, ócio e juventude; ócio e gênero; ócio e terceira idade; ócio em contextos espaciais; ócio urbano; ócio em espaços naturais; ócio digital e as práticas do ócio na vida cotidiana. Todos esses estudos determinam novos âmbitos de conhecimento da experiência.

No dossiê que referenciamos, Kleiber (2012), Roberts (2012), Noguera Tur et al. (2012) e Madariaga e Ortega (2012) refletem, respectivamente, sobre o ócio e terceira idade; o ócio e a juventude; o ócio urbano; e o ócio na cotidianidade como nos dias festivos. Demarcam que, cada vez mais, os períodos de nossa vida se articulam em torno de experiências significativas de ócio,

6 Nesta pesquisa, para conceder o significado atribuído ao tempo livre/ócio, as autoras partiram, no questionário aplicado, de limitar a definição às seguintes opções: "relaxar-se", "conhecer gente agradável”, "fazer o que eu quero" e "aprender algo". Estas quatro definições se referem a quatro dimensões ou formas de entender o tempo livre/ócio: o ócio como momento de descanso e desconexão; o ócio vinculado a relações sociais; o ócio associado a um comportamento individualista e mais isolado, liberado de controles hierárquicos; e por último, o ócio como um tempo também produtivo e de enriquecimento pessoal através da formação e aprendizagem. 
que preenchem de sentido outros múltiplos projetos de vida. Também constatam a relação entre práticas de ócio e saúde como sentido de prevenção de enfermidades ao nível social, conseguindo uma melhora da qualidade de vida cidadã e, por conseguinte, uma economia significativa do gasto público.

Também gostaríamos de ressaltar, neste espaço, a evolução que vem sofrendo o ócio digital, frente ao uso massivo e constante das TIC,'s que não somente têm um valor em si mesmo, mas também criam novos espaços de comunicação, notados nos escritos de Garcia Álvarez et al. (2012). Conforme esses autores, as tecnologias digitais estão também transformando o ócio e a maneira como ele se organiza. Elas têm facilitado o desenvolvimento de novas atividades de ócio, como os jogos digitais, os espaços de interação e a comunicação social em rede, os reprodutores de músicas e audiovisuais, os leitores de livros eletrônicos, as câmeras fotográficas digitais, entre outros. Têm ainda transformado as atividades tradicionais e alterado as dimensões do ócio, incorporando uma nova atividade, com dois valores opostos, ou seja, a experiência de ócio pode ter lugar em um mundo natural e em outro construído digitalmente.

O ócio digital vem a ser um novo espaço para continuar as relações sociais. Sua introdução desafia não somente o conceito de ócio, mas como também suas dimensões. Assim, incute a necessidade de abordá-lo, a partir de uma perspectiva holística, que privilegia o estudo do indivíduo e sua experiência contextual, independentemente de desfrutar de suas atividades de ócio durante seu tempo livre no mundo natural ou no digital (Garcia Alvaréz et al., 2012, p.403).

Essa nova dimensão do ócio - a digitalização de sua experiência - e sua perspectiva holística permitem identificar as transformações que estão se produzindo, dando origem, em diferentes graus, à interpenetração entre os mundos naturais e os construídos digitalmente, assim como à posição do indivíduo na sociedade, propiciando a fusão dos espaços e tempos de trabalho e ócio (interação social presencial e personificada).

\footnotetext{
"As redes sociais, o telefone móvel e seus aplicativos, a mensagem instantânea, executar e compartilhar música digital são atividades que especialmente os jovens desenvolvem durante seu tempo de ócio, não somente para entreterem-se como também para construir sua identidade social, compartilhando símbolos e significados" (Garcia Alvaréz et al ., 2012, p.399)
}

As redes sociais fazem pública uma identidade que vai se construindo com os materiais da experiência vivida durante o tempo de ócio. Espaços digitais, como Facebook, Twitter, Flickr etc., rompem com os limites espaciais e temporais de atividades sociais tradicionais. Neste sentido, desafiam e reproduzem as construções sociais do ócio.

Os videogames, como outro exemplo, configuram na atualidade como uma das atividades lúdicas de maior importância social, em relação ao uso das TIC's, tanto pela quantidade de seus praticantes, quanto pelo impacto econômico de sua indústria (Alvaréz \&Fernández Villarán Ara, 2012 p. 352).

Adotar essa visão do papel das tecnologias digitais na experiência do ócio tem implicações também nos modelos de negócios. O desafio para as empresas tradicionais e de origem digital é 
responder ativamente a essa tendência, materializando a atividade digital e gestando a coprodução de sua oferta com os próprios usuários.

O ócio que os cidadãos do século XXI decidam praticar vai ter uma importância também educacional no seu próprio futuro. Caride Gómez (2012) destaca a educação dos valores e significados que fornece o ócio ao desenvolvimento humano, incidindo em sua capacidade de inovação e transformação da sociedade. "Uma educação que constrói presentes e futuros habitáveis e que relacione as experiências do ócio com os valores que sustentam nossa vida e nossa particular maneira de entender o que é viver" (Caride Gómez, 2012, p.311).

Para finalizar essa primeira seção, gostaríamos também de destacar uma dimensão mais estética do ócio, favorecendo uma experiência mais criativa e cultural, que abre novos horizontes para o desenvolvimento humano. De acordo com Macarena Cuenco (2012), a estética proporciona emoção, alegria e conhecimento. A atitude, o ato, vem a ser o elemento que fundamenta o âmbito estético. A experiência estética se realiza ao tomar uma atitude frente ao seu efeito estético, ao compreendê-la com prazer e ao desfrutá-la, compreendendo-a.

Nesse sentido, a dimensão estética é envolvida de reflexividade. Reflexiva na medida em que diz respeito à medição da experiência do cotidiano. E a arte exemplifica essa dimensão, pois é ativa e criativa. "A experiência estética supõe uma tarefa de reconstrução e integração que envolve plenamente o receptor; não é uma atitude passiva e quieta, mas de participação e coexecução" (Macarena Cuenca, 2012, p.428).Em outro artigo, no qual essa autora trabalha conjuntamente com Manuel Cuenca Cabeza, ambos articulam essa ideia, ao atribuírem ao ócio criativo uma manifestação específica de ócio caracterizada pela vivência de experiências criativas no seu sentido mais global, como criação e recriação. Relacionam-no com distintos modos de viver a cultura e com âmbitos, ambientes, equipamentos e recursos de ócio diferenciados.

\footnotetext{
"É, um ócio cultural caracterizado pela experimentação de vivências separadas do instintivo e do efêmero. Um ócio que nos introduz na visão e desfrute de um mundo mais complexo, mais enriquecedor, satisfatório e humano" (Macarena Cuenco e Cuenca Cabeza, 2013, p.07).
}

De Masi (2000) já falava também, que no século XXI, a sociedade seria envolvida pela ideia de um ócio criativo, que cria valor, divertimento e conhecimento. E a estética, para ele, entre todas as formas de expressão humana, é aquela responsável pela nossa felicidade.

\footnotetext{
"Será a sociedade pós-industrial que, ao contrário, recupera, decididamente, o gosto pela estética: não mais para uma pequena elite, mas uma estética destinada a todos e, não somente uma estética do vestuário e dos ornamentos, mas também a do ambiente de trabalho e das boas maneiras" (De Masi, 2000, p.20)
}

O ócio é arte, defende o autor. O ócio é o alimento da ideação. É pensar e agir! Produzir ideias necessárias e capazes de produzir mudanças para o desenvolvimento da sociedade. O ócio 
que enriquece e que estimula a criatividade é o ócio alimentado por estímulos ideativos e pela interdisciplinaridade.

O processo de todos esses pensamentos levantados e, sinteticamente esboçados aqui, permite entender que o ócio veio sofrendo transformações positivas ao nível conceitual e prático. As reflexões, diferenciadas e complementares, que se observam nos tempos contemporâneos sobre esse fenômeno são nutridas pelo conceito de experiência, que tem como chave de discussão o sujeito que vivencia essas experiências e suas relações com os processos de inovação pessoal, social e econômica.

Percebemos que o ócio, na visão dos autores, representa uma experiência subjetiva, intra e ou interpessoal mais complexa que a realização de alguma atividade específica ou que a disponibilidade de um tempo livre de obrigações. Representa uma maneira de fazer e estar no tempo.

Com essa perspectiva, queremos destacar a evolução e os modos de (re)significação que a experiência de ócio vem representando, como uma maneira de resistência e transformação na dinâmica da vida contemporânea, permitindo um processo de aprendizagem natural e mais integral do desenvolvimento humano.

As ideias apontadas até o presente momento acerca do ócio demonstram o potencial do desenvolvimento do ócio numa perspectiva construtiva.

Nesse sentido, na segunda parte desta reflexão, e provocados com o tema, permitimo-nos também ampliar e avançar tal discussão, centrando nosso olhar para o ócio como direito à alteridade, ao tempo de alteridade - própria e do outro - enquanto "direito à infuncionalidade", da escuta da palavra outra. E, para isso, nutrimo-nos das contribuições do pensamento de Mikhail Bakhtin (2006) e de Ponzio (2010;2013).

\section{TEMPO DE ALTERIDADE}

\footnotetext{
"A vida conhece dois centros de valores, diferentes por princípio, mas correlatos entre si: o Eu e o Outro, e em torno destes centros se distribuem e se dispõem todos os momentos concretos do existir" (Bakhtin, 2006).
}

Uma das principais contribuições trazidas por Mikhail Bakhtin e seu círculo foi a inversão no pólo constituidor do sujeito. Na perspectiva bakhtiniana da construção do sujeito, quem dá as cartas é o outro, e não o eu. O eu constrói-se a partir da relação com o outro, e a isso se dá o nome de Alteridade. Ao escolher a porta da alteridade e não a identidade como constituidora do sujeito, alteramos também o papel do eu para com o outro e, com isso, alargamos o horizonte de sentidos para todas as relações.

A questão da identidade é uma discussão bastante complexa e que transita por campos e setores disciplinares diversos, inclusive os quais discorremos. Identidade é o que define e 
representa o "Eu"7. Nos últimos anos, o Eu foi construído como base para se pensar a própria existência, a partir do ato de pensar e de pensar sobre si.

Bakhtin (2006), filósofo da vida, da linguagem, no entanto, concebe uma nova forma de se impor o Eu; não mais como construtor, mas como constructo. Ele escolhe a categoria OUTRO para pensar a contraposição do Eu. Essa contra-face amplia a possibilidade de relações mais humanizadoras, pois estabelece relações dialógicas materializadas com o Outro, com outras coisas e pessoas.

Miotello (2011) ressalta que o Outro, para Bakhtin, é uma pessoa, mas também é mais que uma pessoa. As coisas do mundo também são Outro para o Eu; tudo que é Outro tem relação com o Eu. As relações entre objetos, entre sujeito e objeto e entre sujeitos se dão na concretude, como materialidade sócio-histórica, como ponto de vista humanizador e humanizado. É o dialogismo de Bakhtin. Essa opção e "revolução bakhtiniana" consiste no deslocamento da atenção da identidade à alteridade.

A Bakhtin interessa que o Eu seja pensado pelo Outro. O pensar do Outro descola-me e constitui-me sujeito na relação com ele e com os outros. Para ele, interessa a responsabilidade de como responder ao Outro e pelo Outro, sem álibi. Interessa mostrar que o valor do Outro é esteticamente produtivo.

Bakhtin ocupa-se da palavra para evidenciar nela a presença de outra palavra que a torna inteiramente dialógica. A iniciativa e o ponto de partida do diálogo são sempre do Outro. Ele se dá "apesar de mim".

\begin{abstract}
"Cabe ao outro me fazer viver, existir, e para isso tem que me incompletar. Ele tem essa atividade como responsabilidade única e pessoal. Ele precisa me responder, se dirigir a mim como respondente sempre. Tarefa do outro no diálogo é a resposta. Precisa romper esse limite identitário fechado, pronto e estabelecido por mim. Esse rompimento vai permitir o alargamento do meu ser por um outro ser que também se alarga nesse mesmo movimento, pois que também é penetrado profundamente por um eu ativo e respondente" (Miotello, 2013, p.52).
\end{abstract}

Esse pensador traça um caminho no qual sua natureza se dá na relação; numa atividade entre dois ou mais. E toda relação é uma soma, logo, exijo o outro sempre, deslocando- me, incompletando- me, constituindo- me.

O sujeito para Bakhtin é um signo e o que o define é a alteridade. É o Outro que dá existência ao Eu e é na presença do Outro que o eu se descobre singular. O sujeito é também respondente e responsável, isto é, a cada palavra, ação do Outro, da incompletude, cria-se uma contrapalavra, uma escolha.

Enquanto escutamos, estamos falando, aprendendo, alargando e compreendendo. $\mathrm{O}$ benefício da escuta na formação do eu é a porta para a ética e a estética da existência do singular.

7 Gostaríamos de ressaltar que em todos os momentos que destacarmos o pronome Eu, não representa literalmente a concordância ortográfica da primeira pessoa do singular, mas a ideia teórica e filosófica expressa e citada pelos autores de referência Bakhtin e Ponzio. 
Assim é que Bakhtin vai definir seu caminho de pensar as relações de alteridade: pelo encontro de palavras (Ponzio, 2010).

Não são os encontros entre "tu e eu" apenas (no campo da possibilidade de apenas dois homo sapiens estarem frente a frente); mas as nossas palavras precisam se encontrar. Elas são a tensão. Elas trocam sentidos, modos de pensar a realidade e o mundo. Elas trocam valorações, entram em contradição.

Se o que vai me alterar é o encontro de palavras, de signos, devo me abrir ao encontro, devo procurar a palavra outra, diferente da minha palavra. Devo me colocar na escuta da palavra do outro.

Ponzio (2010) ressalta que, o sujeito da escuta é o eu, mas esse eu está determinado pelo Outro, pois escutar é ouvir o Outro, a voz do Outro, dar um tempo ao Outro. Ao iniciar a questão pelo escutar, que só pode ser ouvir o Outro (seja o Outro eu ou o Outro de mim), uma visão diferenciada se anuncia no terreno comum, isto é, no terreno da liberdade da palavra.

Nossas reflexões e práticas cotidianas potencializam-se com o pensamento de Bakhtin. Para este recorte, fomos provocados a pensar um pouco o ócio por esse viés. E, pensar o ócio é inseri-lo nessa compreensão da alteridade, do tempo de alteridade, do encontro do Outro/de palavras, que gera interação, experiência, vivência.

Ponzio $(2010,2013)$, nutrido pelas ideias de Bakhtin, ajuda-nos a prosseguir com e a contextualizar essa discussão. Refere-se ao direito à alteridade, ao tempo de alteridade, tempo do outro, de uma escuta "viva" do "humano", nas suas diferenças singulares.

Em contraposição à "produtividade", que move e orienta todo o sistema de comunicaçãoprodução, o direito à alteridade se especifica enquanto "direito à infuncionalidade". O direito à infuncionalidade é o direito a valer por si, como alteridade não relativa, que faz existir cada um de nós, não simplesmente como indivíduo, mas como único, como absolutamente Outro, não substituível, não intercambiável.

O mundo de trabalho de hoje, da troca e do consumo - a globalização - é caracterizado pela comunicação-produção. Desenvolvimento, eficiência e competitividade são valores fundamentais nos tempos atuais. A comunicação-produção de hoje, porém, tem um caráter "destrutivo", não apenas em relação ao produto e ao trabalho, mas também em relação à qualidade de vida e, sobretudo, em relação à palavra tornada palavra funcional, eficiente, produtiva, identitária, conformada à realidade, à ordem vigente, confinada nos lugares-comuns do discurso dominante (Ponzio, 2010, p.144).

"O infuncional é o humano" (Ponzio, 2010. p.142). Nessa afirmação, o autor nos alerta que o direito à infuncionalidade assume um caráter subversivo, revolucionário, em que o homem não é um recurso, meio reduzido a capital, que precisa ser valorizado por toda a sua vida ativa; mas um fim, socialmente útil.

É possível entrever, então, o que está em jogo nessa reflexão: a relação identidade/alteridade. 
No mundo contemporâneo mercadológico, algumas diferenças são aprofundadas e delas se constroem identidades que conformam grupos consumidores pelos quais os indivíduos transitam, vestindo a cada vez uma camisa de força em nome da liberdade, da mobilidade, metonímia do direito do ir e vir como função do mercado.

Aqui podemos reconhecer a identidade como armadilha, mas Geraldi (2010) aponta para outro caminho, a busca por semelhanças entre os diferentes: um ato solidário de compreensão; a identidade como acontecimento da participação entre dois centros de valor (EU-OUTRO): a aproximação. Aproximação do Outro, junto com ele, como força criadora na participação com o mundo.

É possível entrever então que o que está em jogo nessa discussão é a relação identidade/alteridade, que é também o que está em jogo na possibilidade de uma palavra outra na interação, consistindo assim na disponibilidade de tempo para o outro, para o outro de si e para/ou/por si. O tempo disponível para a alteridade, própria e do outro, é o tempo criativo, da escuta que se dá pela aproximação, em comum-união, comunhão, Outro-Eu.

Deste modo, uma experiência de ócio deveria resultar numa singular, irrepetível possibilidade de exigir sempre a presença do Outro, da diferença não indiferente no ato da vida, da convivência, das interações, das aprendizagens.

A identidade, que se identifica e se reconhece numa forma social, que faz a riqueza social consistir em tempo de trabalho, impede, nega a escuta, uma vez que a escuta consiste justamente na disponibilidade de tempo para o Outro. Já a alteridade é o movimento do tempo disponível, própria e do Outro, do "trabalho criativo", do tempo da escuta.

Conforme Ponzio (2010), a palavra que escuta é a palavra do tempo disponível para a palavra outra. Para ele o tempo disponível não é o tempo deixado livre pelo trabalho, isto é, tempo de descanso como intervalo, funcional ou em relação ao trabalho. O tempo disponível é o tempo livre do trabalho, é o tempo social disponível. Este tempo cresce à medida que cresce a automação e será reconhecido como uma riqueza social.

“O tempo do trabalho-mercadoria é o tempo da indiferença, da generalidade, da quantificação. Já o tempo disponível é o tempo da não-indiferença, da singularidade, da qualificação. Neste, a relação social baseada na sua identidade compreende uma relação social de alteridade, de outro em relação a outros" (Ponzio, 2010, p.150).

Notamos, portanto, com essa mudança de perspectiva, a importância de pensarmos a categoria do Outro, da alteridade, para pensar as relações humanas, para pensar as experiências e para a vida.

E pensar o ócio nessa perspectiva da alteridade é pensá-lo como integrante do processo das relações, das experiências, como elemento que permite o encontro com o Outro, entre diferentes que se mantêm diferentes, na aproximação, na participação.

É entendê-lo como o tempo disponível para o Outro, para a alteridade própria e do Outro, o tempo que tem uma efetiva consistência, uma materialidade específica, uma riqueza social, 
criativa e livre. É reconhecer que ele pode representar mais um caminho capaz de aproximar o homem de seu projeto de vida, de seu projeto de dizer na existência.

\section{CONSIDERAÇÕES FINAIS}

De acordo com nosso principal objetivo, que foi o de trazer um levantamento e algumas reflexões sobre os aspectos concebidos ao fenômeno do ócio em nossa época, pudemos observar que distintas abordagens têm contribuído para dar vitalidade e sustentação ao assunto, desde conceitos teóricos até aspectos mais amplos da aplicação e problematização do tema, bem como suas interfaces disciplinares e transdisciplinares. De acordo com os pesquisadores que colaboram com os estudos e pesquisas do Instituto de Estudos do Ócio da Universidade de Deusto - Espanha e relacionados na discussão acima, o ócio, ao longo do último século, experimentou um processo de modernização, democratização e crescimento de seus estudos, o que permitiu uma evolução de seus conceitos. De atividades ou práticas ligadas ao consumo, até ser explorado como ócio digital, passou a ser compreendido também como relacionado a práticas para novos modos de vida e como experiência, que tem como chave de discussão o sujeito que vive essas experiências.

Alguns elementos discursivos, como consumo, lazer, trabalho, tecnologia e subjetividade, são articulados à temática e fazem parte da reflexão que se caracteriza por um pensar comprometido com a vivência do ócio, aqui tratada como experiência positiva e transformadora que se entrelaça ao mundo social elaborado na contemporaneidade consumista.

O ócio vem sendo definido como uma área específica da experiência humana com seus benefícios e elementos próprios. E ao ser entendido como experiência da pessoa e fenômeno da sociedade contemporânea, tem se nutrido de muitas frentes disciplinares para compreendê-lo em sua globalidade.

Do mesmo modo, também trouxemos para essa discussão uma nova maneira de olhar para o ócio, para as relações e para o mundo, pela porta da alteridade, a partir das contribuições da filosofia de Mikhail Bakhtin e de Augusto Ponzio.

Fomos provocados a ampliar e integrar essa discussão, deslocando o eixo de pensar o ócio como direito à alteridade, ao tempo de alteridade - própria e do Outro - enquanto "direito à infuncionalidade", da escuta da palavra outra. Esse Outro, essa inversão do olhar, consiste na imensa contribuição para as nossas ideias, experiências e para a vida, pois possibilita novas relações humanas. A busca do Outro, da diferença, não indiferente é o movimento da incompletude, do alargamento, da ampliação dos horizontes. É no encontro com o Outro, da alteridade, que se dá a prática da escuta, da compreensão ativa-responsiva.

A filosofia do encontro pressupõe o jogo dialógico bakhtiniano, em que o sentido se constrói na relação, na concretude das relações, da qual resulta a afirmação de sujeitos ativos; portanto, evidência diferentes vozes, sentidos e, no lugar da centralidade do Eu, dá espaço à centralização do Outro, da alteridade, pois ela se revela constituidora em que a identidade é posterior à alteridade. 
Com essa mudança de perspectiva, percebemos a importância de pensarmos a categoria do Outro, da alteridade, para pensar as relações humanas, para pensar as experiências e para a vida.

E pensar o ócio nessa perspectiva da alteridade é pensá-lo como integrante do processo das relações, das experiências; como elemento que permite o encontro com o Outro, entre diferentes que se mantêm diferentes, na aproximação, na participação. É entendê-lo como o tempo disponível para o Outro, para a alteridade própria e do Outro, o tempo que tem uma efetiva consistência, uma materialidade específica. É compreendê-lo como constituinte da vida, como elemento de aprimoramento humano, considerando a relação com o outro, precisamente, a possibilidade de descobrir a alteridade no próprio coração da identidade.

Tudo é experimentado, vivenciado, seja por meio das palavras ou de atos e expressões. Iniciar um pensamento e uma prática pelo Outro é iniciar um processo que descentraliza e desloca o Eu, os papéis, os lugares, os discursos. É criar a multidão de vozes.

Reforçamos, no entanto, a ideia de que é no reconhecimento do Outro, na relação de alteridade em nossas práticas cotidianas, que vamos nos constituindo e nos conferindo a possibilidade de sermos livres e melhores na vida que escolhemos viver e experienciar e na ação que assumimos pôr em curso.

Sabemos que a discussão não se esgota aqui. Ela ainda nos inquieta e nos impulsiona a buscar as contra palavras que aprimoram, somam e integram os estudos sobre o ócio nos tempos contemporâneos.

\section{REFERÊNCIAS}

Alvarez, A. M \& Fernández-Villarán Ara, A. (2012). Impacto econômico del ócio em el siglo XXI. Arbor: Ciência Pensamento e Cultura. 754. Pp. 351-363. Acesso em: 27 out. 2013. Disponível em: < http://arbor.revistas.csic.es/index.php/arbor>.

Bakhtin, M. (2006). Estética da criação verbal. 3.ed. São Paulo: Martins Fontes.

Caride Gómez, J. A. (2012). Lo que el tiempo educa: el ocio como construcción pedagógica y social. Arbor: Ciência Pensamento e Cultura. 754, pp. 301-313. Acesso em: 27 out. 2013. Disponível em: < http://arbor.revistas.csic.es/index.php/arbor>.

Cuenca Amigo, J. (2012). Génesis de la comprensión experiencial del ócio em la modernidad tardia: transformaciones Del concepto de vivencia. Arbor: Ciência Pensamento e Cultura. 754, pp. 315-325. Acesso em: 27 out. 2013. Disponível em: < http://arbor.revistas.csic.es/index.php/arbor>

Cuenca Cabeza, M. \& Goytia Prat, A. (2012). Ocio experiencial: antecedentes y características. Arbor: Ciência Pensamento e Cultura. 754, pp. 261-281. Acesso em: 27 out. 2013. Disponível em: < http://arbor.revistas.csic.es/index.php/arbor>

Cuenca Cabeza, M. \& Macarena Cuenca, M.L.A. (2013). O encontro entre o ócio e a cultura: Reflexões sobre o ócio criativo desde a investigação empírica. Revista Lusófona de Estudos Culturais. v.1, n.2, pp. 3-26. Acesso em: 19 fev. 2015. Disponível em: <http://estudosculturais.com/revistalusofona/index.php> 
De Masi, D. (2000). O ócio criativo. 3.ed. Rio de Janeiro. Sextante.

Fradua, I. A. \& Cabrera, M.S. (2012). El ócio como valor en la sociedad actual. Arbor: Ciência Pensamento e Cultura. 754, pp. 283-291. Acesso em: 27 out. 2013. Disponível em: < http://arbor.revistas.csic.es/index.php/arbor>

García Alvarez, E., Sintas, J. L. \& Martínez, A. S. (2012). Retos y tendencias del ocio digital: transformación de dimensiones, experiencias y modelos empresariales. Arbor: Ciência Pensamento e Cultura. 754, pp.396407. Acesso em: 27 out. 2013. Disponível em: < http://arbor.revistas.csic.es/index.php/arbor $>$

Geraldi, J.W. (2010). Ancoragens: estudos bakhtinianos. Carlos: Pedro \& João Editores.

Kleiber, D. A. (2012). Optimizing leisure experience after 40. Arbor: Ciência Pensamento e Cultura. 754, pp. 341-349. Acesso em: 27 out. 2013. Disponível em: < http://arbor.revistas.csic.es/index.php/arbor>

Macarena Cuenco, M. L. A. (2012). Propuesta de líneas de mejora de la experiencia operística desde el ocio creativo. Arbor: Ciência Pensamento e Cultura. 754, pp. 427-440. Acesso em: 27 out. 2013. Disponível em: < http://arbor.revistas.csic.es/index.php/arbor>.

Madariaga, A. \& Ortega, C. (2012). Ocio festivo: Cambios relevantes em La percepción y organización de las fiestas. Arbor: Ciência Pensamento e Cultura. 754, pp. 365-378. Acesso em: 27 out. 2013. Disponível em: < http://arbor.revistas.csic.es/index.php/arbor>.

Miotello, V. (2011). Apresentação - O diferente sou eu para o outro- Teses sobre a Alteridade rascunhadas à sombra e à luz de Bakhtin. In: Miotello, $\mathrm{V}$ (org.). O diferente instaura o diferente: compreendendo as relações dialógicas. São Carlos: Pedro \& João Editores, pp. 7-12.

Miotello, V. (2013). Pensando questões sobre a alteridade e a identidade. In: Miotello, V. \& Gege (Grupo de Estudos dos Gêneros do Discurso-UFSCar). Palavras e Contrapalavras: circulando pensares do Círculo de Bakhtin. São Carlos: Pedro \& João Editores, pp. 49-66.

Noguera Tur, J., Martinéz, A. F \& Spiegelhalder, M. R. (2012). De complemento a motor: La transformación de la función del ocio y turismo en las estrategias de desarrollo local. El caso de la recuperación y valorización del patrimônio cultural. Arbor: Ciência Pensamento e Cultura. 754, pp. 379-393. Acesso em: 27 out. 2013. Disponível em: <http://arbor.revistas.csic.es/index.php/arbor

Panosso Netto, A. (2010). Experiência e turismo: uma união possível. In: Panosso Netto, A E Gaeta, C. (orgs). Turismo de experiência. São Paulo: Editora Senac São Paulo, pp. 43-56.

Pine, J B. li \& Gilmore, J, H. (1999). The experience economy: work is theatre and every business a stage. Boston: Harvard Business School Press.

Ponzio, A. (2010). Procurando uma palavra outra. São Carlos: Pedro \& João Editores. (2013). No círculo com Mikhail Bakhtin. São Carlos: Pedro \& João Editores.

Rifkin, J. (2001). A era do acesso. 3. ed. São Paulo: Makron Books. 
Roberts, K. (2012). El ocio de los jóvenes en la sociedad contenporánea. Arbor: Ciência Pensamento e Cultura. Madrid. 754, pp. 327-337. Acesso em: 27 out. 2013. Disponível em: < http://arbor.revistas.csic.es/index.php/arbor>.

Silvestri, K.V.T \& Bassinello, P.Z. (2012). A estética enquanto método. In: Miotello, V. \& Gege (Grupo de Estudos dos Gêneros do Discurso - UFSCar). Palavras e Contrapalavras: enfrentando questões da metodologia bakhtiniana. São Carlos: Pedro \& João Editores, pp. 56-65.

Trigo, L.G.G.T. (2010). A viagem como experiência significativa. In: Panosso Netto, A \& Gaeta, C. (orgs). Turismo de experiência. São Paulo: Editora Senac São Paulo, pp. 21-42. 